\title{
Sexual size and development time dimorphism in a parasitoid wasp: an exception to the rule?
}

\author{
JeFFrey A. HARVEY ${ }^{*}$ and MichaEl R. STRAND ${ }^{2}$ \\ ${ }^{1}$ Department of Multitrophic Interactions, Netherlands Institute of Ecology, Centre for Terrestrial Ecology, P.O. Box 40, 6666 ZG \\ Heteren, The Netherlands; e-mail: j.harvey@nioo.knaw.nl \\ ${ }^{2}$ Department of Entomology, University of Georgia, 420 Biological Sciences Building Athens, Georgia 30602 U.S.A.
}

Key words. Development, parasitoid, sexual dimorphism, Microplitis mediator, Pseudoplusia includens, size

\begin{abstract}
Sexual dimorphisms in adult size (SSD) and development time (SDTD) occur in many groups of organisms. In insects, some of the best examples occur in parasitoid wasps where most studies report that females are larger than males but take longer to develop. Sex-specific differences in the effects of size on reproductive success is generally regarded as the main factor responsible for SSD in parasitoids. Most studies also assume that development time must be extended in order to achieve larger size. Here, SSD and SDTD were compared in the solitary endoparasitoid, Microplitis mediator that develops in larvae of the moth Pseudoplusia includens. The relationship between male and female body size and development time were isometric in $M$. mediator, but contradict most predictions of parasitoid development models. Across first to fourth instars at parasitism, male wasps were consistently larger than females but completed their development significantly faster. The longer development time in female wasps was due primarily to an extended pupal phase, whereas the duration of larval development did not vary significantly with offspring sex. Secondary sex ratios (percentage male) also did not vary with host instar. We conclude that SSD in $M$. mediator is not only a function of extended development time, but also because of several possible factors: (i) selection favours an increase in male size (relative to female size); (ii) female size is constrained because of predation risk, (iii) as a cost of reducing the cost of inbreeding or (iv) constraints on egg maturation rate. We argue that failure to look carefully at how parasitoids grow can lead to incorrect conclusions about the basis or significance of SSD.
\end{abstract}

\section{INTRODUCTION}

Intraspecific differences in resource allocation to male and female offspring has long been a subject of interest to evolutionary biologists (Rensch, 1959; Calder, 1984). Sexual-size dimorphisms occur in many dioecious organisms and are usually attributed to either the differential benefits of size to reproductive success (Fairbairn \& Preziosi, 1994; Schulte-Hostedde et al., 2001) or the differential risks of size for adult mortality (Vollrath \& Parker, 1992). Males are frequently larger than females in mammals and birds (Greenwood \& Wheeler, 1985; Karubian \& Swaddle, 2001), whereas this pattern is often reversed in other vertebrate groups (Ghiselin, 1974; Shine \& Crews, 1988).

Sexual size dimorphisms also occur in invertebrates. Among insects, many studies on sexual-size dimorphisms have focused on parasitoid wasps that lay their eggs in or on other insects (the host) and whose progeny develop by feeding on host tissues (Godfray, 1994). Since offspring derive all resources for development from one host, a direct relationship exists between host quality and the fitness of parasitoids. Most parasitoid wasps are also haplodiploid with unfertilized eggs developing into males and fertilized eggs developing into females. This allows adult females to potentially control the sex of the offspring they lay on hosts of differing quality. Size is often considered the most important measure of host quality, because parasitoid size tends to increase with host size and in turn is correlated with other measures of fitness like fecundity and longevity (Strand, 2000, 2002).

The relationship between host size and parasitoid size is often most direct for idiobiont parasitoids that attack nongrowing host stages (eggs, pupae) or that paralyze their host at oviposition. For idiobionts, host resources are fixed and larger hosts tend to produce larger parasitoids (Corrigan \& Lashomb, 1990; Heinz, 1996). However, increased size comes at the potential cost of longer development times, because larger hosts take longer to consume (Harvey \& Gols, 1998). Many koinobiont parasitoids, in contrast, attack larval stage hosts that continue to grow after parasitism and whose size can change considerably between oviposition and completion of parasitoid development. As a result, the relationship between host size at oviposition, parasitoid size and development time is less direct for koinobionts and depends on a number of ecophysiological considerations (Mackauer \& Sequeira, 1993).

Parasitoids also frequently exhibit sexual-size dimorphisms (SD) in adult body size (SSD) and/or development time (SDTD). In her survey of the literature, Hurlbutt (1987) found that females on average are larger than males in 18 of 21 families of parasitoid wasps. More recent studies report similar trends and also indicate that increased female size is due primarily to female larvae feeding longer than male larvae (Sequeira \& Mackauer, 1992; Mackauer, 1996; Harvey, 2000). While larger size

\footnotetext{
* Corresponding author.
} 
presumably benefits both sexes, the trend of female parasitoids being larger than males is most often attributed to the idea that females benefit more from increased size than males (Charnov, 1982). This benefit could be due to factors such as size increasing female fecundity more than male sperm production (Werren, 1984; Visser, 1994), or larger size benefitting location and successful parasitism of hosts by females more than mating success of males (Gerling et al., 1990; Ellers et al., 2001).

Many empirical studies have demonstrated that adult females accurately assess host size before ovipositing, and preferentially allocate female offspring to large hosts and male offspring to small hosts (Schmidt \& Smith, 1985; Waage \& Godfray, 1985; Takagi, 1986; Strand, 1988; Hardy et al., 1992; Mayhew, 1998). However, almost all studies of SSD and SDTD in parasitoids involve idiobionts rather than koinobionts. In addition, the benefits of size for males or the potential costs of development time for either sex is poorly understood for almost all parasitoids. Large males may gain in terms of fitness where there is strong male-male competition for access to females, particularly for gregarious species that emerge from clustered cocoons in aggregated sites. On the other hand, where females are scarce or dispersed, large size may increase male longevity and mate-finding ability, particularly where the metabolic costs of dispersal are high (Bernal et al., 2001). In the case of female parasitoids, more rapid development and early emergence may be favored under conditions where host populations grow rapidly or overlapping generations are available (Godfray, 1994). Alternatively, early emerging males may be able to mate with more females than latereclosing males (Fagerstrom \& Wiklund, 1982; Parker \& Courtney, 1984).

In this study, we examined growth and development of the solitary koinobiont endoparasitoid, Microplitis mediator Haliday (Hymenoptera: Braconidae) in the soybean looper Pseudoplusia includens Walker (Lepidoptera: Noctuidae). To determine if each parasitoid sex exploits a given amount of host resources differently, we compared the development of male and female parasitoids in hosts of equivalent quality (e.g. the same stage or size at oviposition). Contrary to the trends usually reported for idiobionts, our results indicate that $M$. mediator males are consistently larger and emerge as adults earlier that females.

\section{METHODS AND MATERIALS}

\section{Biology of Microplitis mediator and rearing}

Microplitis mediator is a solitary, larval endoparasitoid native to Europe and Asia that attacks a number of moth species in the family Noctuidae. Across its native range, $M$. mediator primarily parasitizes armyworms like Mamestra brassicae and Pseudaletia separata. Microplitis mediator has also been introduced into North America where it has been tested as a biological control agent for Mamestra configurata (Arthur \& Mason, 1986) and where it parasitizes other noctuids including Pseudoplusia includens (Kadash et al., 2003). M. mediator parasitizes first (L1)-fourth (L4) instar $P$. includens, but usually rejects this host in the final (fifth) instar. Females locate hosts with their antennae and oviposit into the hemocoel of the host caterpillar (Arthur \& Mason, 1986). Eggs normally hatch within 2-3 days, and first instar parasitoids possess large mandibles that they use in combat to kill inter- or intraspecific competitors. Following the completion of larval development, the final instar parasitoid larva emerges from the host by rasping through the integument of the host between the fifth and sixth abdominal segments. The wasp larva then spins a cocoon adjacent to the host carcass, pupates, and then emerges as an adult wasp by chewing its way out of the cocoon. Like other parasitoid species in the higher Microgastrinae, larvae of $M$. mediator exclusively consume host hemolymph during development and thus exploit only a small fraction of available host resources (Harvey et al., 2000; Harvey \& Strand, 2002). The adaptive significance of the hemolymph-feeding strategy is discussed in more detail by Brodeur \& Vet (1994), Harvey et al. (2000) and Harvey \& Strand (2002).

Cultures of hosts and parasitoids were reared at $27^{\circ} \pm 2^{\circ} \mathrm{C}$ with a $65 \pm 5 \%$ rh and a $16 \mathrm{~L}: 8 \mathrm{D}$ photoperiod. $P$. includens larvae were reared on artificial diet as described by Strand (1990). Adult moths were maintained in 41 plastic cups with paper towel secured by elastic bands, and fed on $20 \%$ sugar solution. Female moths oviposit directly onto the paper towel; after collection, the eggs were surface sterilized using a $2 \%$ bleach solution, and were allowed to hatch directly onto diet in plastic rearing boxes. Microplitis mediator was reared on $P$. includens larvae by placing 5 mated adult female wasps into a Petri dish (20 cm dia.) containing approximately $50 \mathrm{~L} 2$ larvae of $P$. includens for $24 \mathrm{~h}$. After this time, wasps were returned to cultures and hosts were reared on artificial diet until the egression and pupation of $M$. mediator.

\section{Development of $M$. mediator in L1-L4 P. includens}

At $27^{\circ} \mathrm{C}$, the duration of first-fourth stadia of $P$. includens is two days: on the first day the larva feeds, and on the second the larva enters apolysis followed by ecdysis to the next instar (Strand, 1990). Each instar for $P$. includens was identified using established staging criteria that include larval body mass and head capsule widths. Cohorts of hosts representing mid L1-L4 instars were parasitized by presenting larvae individually to mated female parasitoids in plastic vials. To ensure that hosts were not self-superparasitized, parasitism of each host was visually monitored. Parasitized hosts were individually transferred to small cups containing excess diet. After the parasitoid larvae had egressed from the host and pupated, the remaining diet (and host carcass) was removed. At eclosion, wasps were sexed and the fate of parasitized hosts was determined. Parasitoid development time was recorded in days (monitored up until $1700 \mathrm{~h}$ on the day of emergence) and was divided into three categories: overall egg-to-adult development time, which was further broken down to compare the duration between oviposition and larval egression (cocoon production), and the duration between cocoon production and adult eclosion. In order to measure adult parasitoid size (fresh body mass), newly emerged wasps were anesthetized with $\mathrm{CO}_{2}$, then weighed individually on a Cahn 29 microbalance (accuracy $1 \mu \mathrm{g}$ ). Finally, the fate of parasitized hosts was determined (broken down into the following criteria: adult wasp, adult moth [= encapsulated parasitoid], precocious host death, and larval-pupal host intermediates). Secondary (= emerging) parasitoid sex ratios were also recorded. Experiments with all day- and -instar combinations were performed at the same time to minimize any potential effects of variability in abiotic conditions. 
(A)

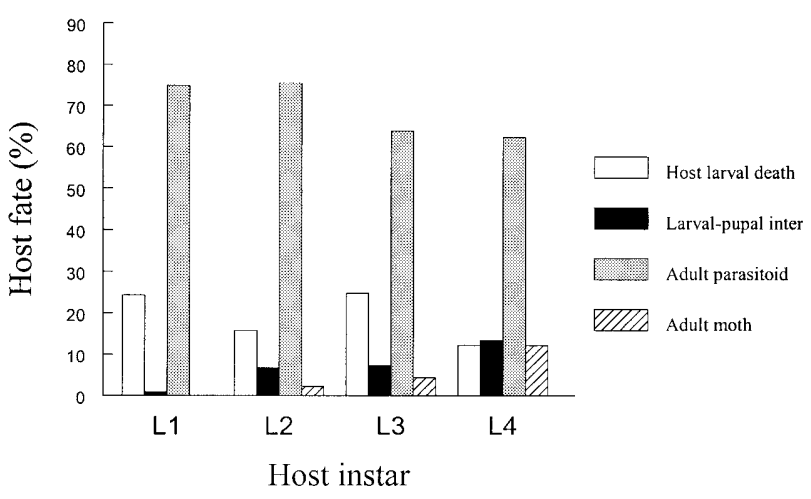

(B)

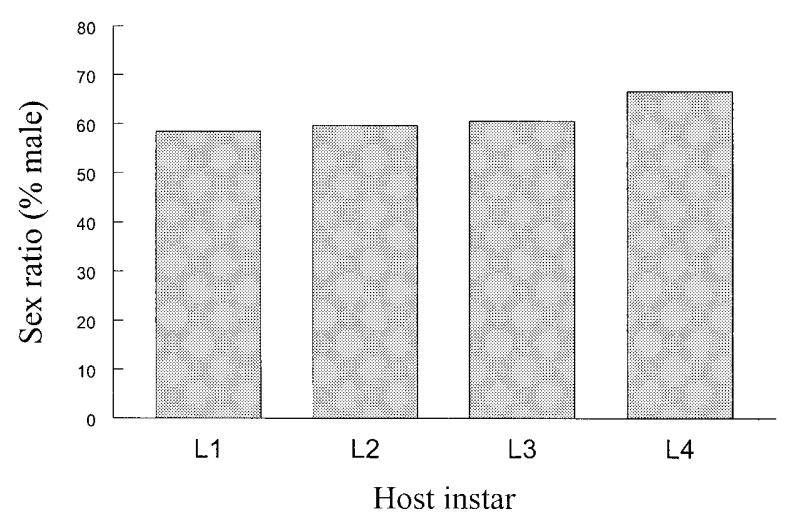

Fig. 1. Parasitoid/host fate (a) and offspring sex ratios (b) in Microplitis mediator developing in first to fourth instars of its host, Pseudoplusia includens. Line bars in (b) represent 95\% confidence intervals. Sample sizes: (a) L1 $=111, \mathrm{~L} 2=89$, L3 $=$ $69, \mathrm{~L} 4=82 ;$ (b), L1 $=77, \mathrm{~L} 2=62, \mathrm{~L} 3=38, \mathrm{~L} 4=49$.

\section{Evaluating SD in M. mediator}

Sexual dimorphism in parasitoids has often been expressed by comparing the ratio of female:male development time and/or size (Mackauer, 1996). Here, the ratio of overall egg-to-adult development time and emerging adult body mass were compared with offspring sex in different instars of $M$. mediator.

\section{Statistical analyses}

Data on parasitoid fate, offspring sex ratio and ratios of male : female parasitoid size were analysed by $\chi^{2}$; the remaining data on parasitoid development time (broken down separately into overall development time in days, days from egg-to-pupa and days from pupa to adult), adult parasitoid size, and remaining host mass after larval parasitoid egression from the host were compared by means of analysis of covariance (ANCOVA) with host instar parasitized as factor and offspring sex as covariate.

\section{RESULTS}

\section{Development of $M$. mediator in L1-L4 P. includens}

The fate of parasitized hosts varied significantly with host instar $\left(\chi_{9}^{2}=36.35 P<0.01\right)$. Although parasitoid survival varied little across the different host stages at parasitism (and was approximately $62-75 \%$ ), the rate of encapsulation and formation of larval-pupal host intermediates (in which no wasp successfully emerged) were higher in later instars (Fig. 1a). Alternatively, offspring sex ratio did not vary significantly with host stage $\left(\chi_{3}^{2}=\right.$

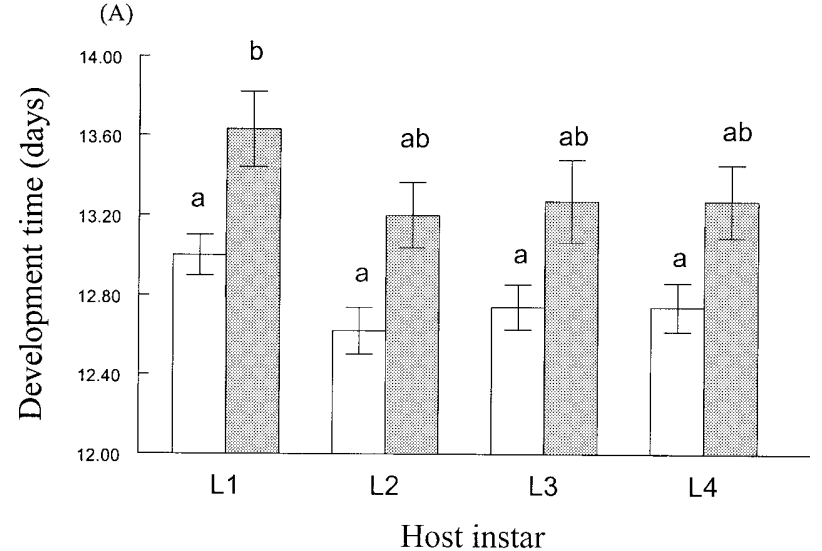

(B)

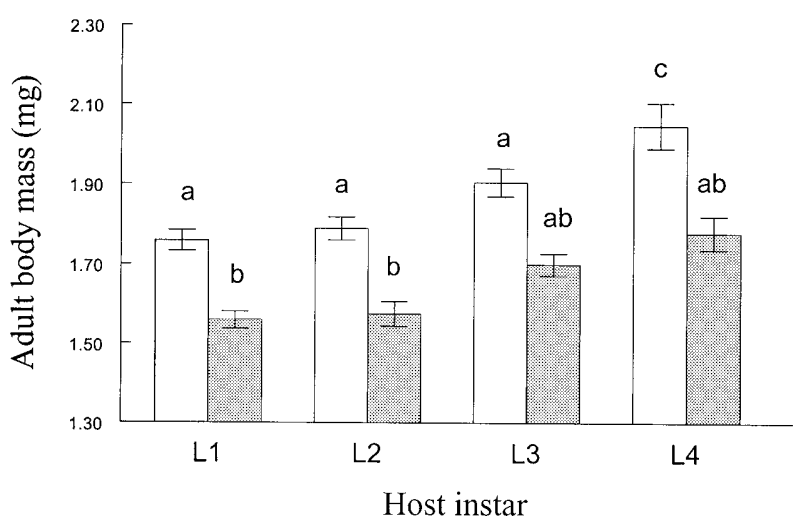

Fig. 2. Development of Microplitis mediator in first to fourth larval instars of its host, Pseudoplusia includens. (a) Egg-to adult development time; (b) emerging adult wasp size, in mg. Open bars = male wasps, shaded bars $=$ female wasps. Line bars represent standard error of the mean. Bars with different letters are significantly different $(P<0.05$; Tukey tests). Sample sizes: males, $\mathrm{L} 1=45, \mathrm{~L} 2=37, \mathrm{~L} 3=23, \mathrm{~L} 4=33$; females, $\mathrm{L} 1=32$, $\mathrm{L} 2=25, \mathrm{~L} 3=15, \mathrm{~L} 4=16$.

$1.09, P>0.05)$. From $58-65 \%$ of wasps emerging from L1-L4 hosts were male, even though the offspring sex ratio increased, albeit slightly, with host instar (Fig. 1b).

In $M$. mediator, overall (egg-to-adult) development time varied significantly with host stage attacked $\left(F_{3,221}=\right.$ $3.59, P=0.02)$ and co-varied significantly with offspring sex $\left(F_{1,221}=30.15, P<0.001\right)$. Looking more specifically at different phases of parasitoid ontogeny, development time from egg to cocoon varied significantly with host instar $\left(F_{3,221}=7.77, P<0.001\right)$ but did not co-vary significantly with offspring sex $\left(F_{1,221}=2.59, P=0.169\right)$. By contrast, the period between cocoon formation and adult eclosion in $M$. mediator did not vary significantly with host instar $\left(F_{3,221}=1.80, P=0.147\right)$ but did co-vary significantly with offspring $\operatorname{sex}\left(F_{1,221}=35.24, P<0.0001\right)$. Across the different host instars at parasitism, overall parasitoid development time decreased marginally but consistently with host stage at parasitism, with male wasps completing development more rapidly than females in all instars of $P$. includens (Fig. 2a). However, the longer development time in females is mostly attributable to an extended pupal phase. 


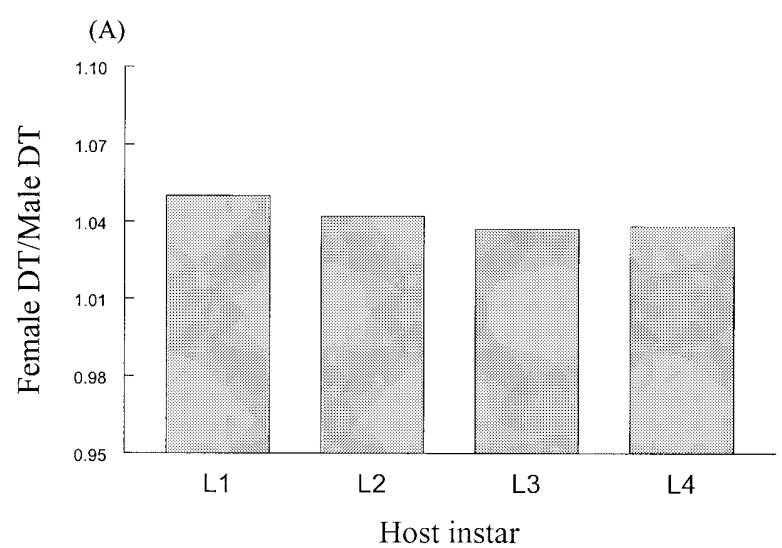

(B)

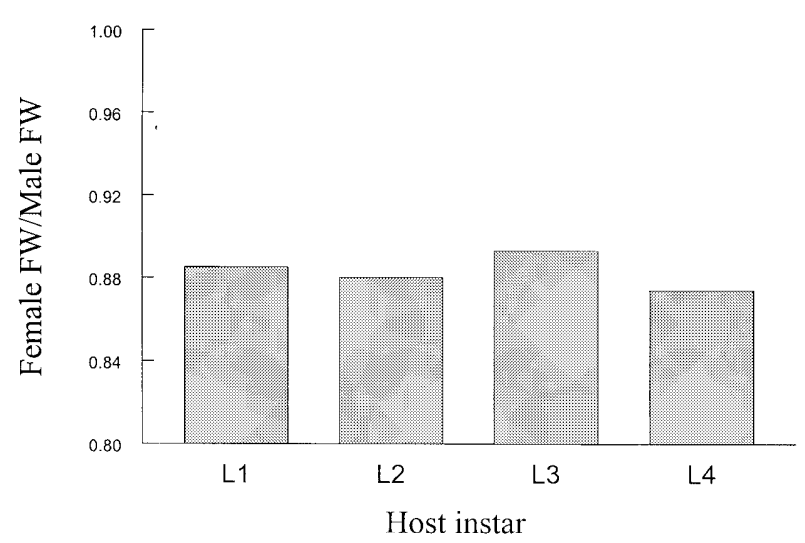

Fig. 3. Ratios of male:female (a) development time and (b) emerging adult size, for Microplitis mediator developing in first to fourth larval instars of its host, Pseudoplusia includens. Data is based on sample sizes as in Fig. 2.

Emerging adult parasitoid size also varied significantly with host stage $\left(F_{3,221}=21.59, P<0.0001\right)$, and co-varied significantly with offspring $\operatorname{sex}\left(F_{1,221}=69.97, P<\right.$ $0.0001)$. Parasitoid size increased almost linearly with host stage at parasitism, with wasps emerging from L4 hosts being some $25-30 \%$ larger (in terms of fresh body mass) than counterparts developing in L1 hosts (Fig. 2b). Across all host instars, male parasitoids were also consistently $10-15 \%$ larger than females. In this study, 28 out of 138 newly emerged males exceeded $2 \mathrm{mg}$ in weight, whereas only 2 out of 87 newly emerged females exceeded this size.

Fig. 3 shows the ratios for female:male development time and adult size in $M$. mediator across the different instars of $P$. includens at parasitism. No significant differences were observed in the ratios for development time $\left(\chi_{3}^{2}=0.006, P>0.05\right)$ or offspring size $\left(\chi_{3}^{2}=0.010, P>\right.$ $0.05)$. Irrespective of host instar parasitized, the ratios were consistent ( $=$ isometric) with male wasps completing development more rapidly than females and also being significantly larger.

\section{The effect of offspring sex on host growth}

The relationship between host instar parasitized and the terminal mass of the host carcass after larval parasitoid egression was highly significant $\left(F_{3,221}=346.23, P<\right.$ $0.0001)$ although final host size did not co-vary signifi-

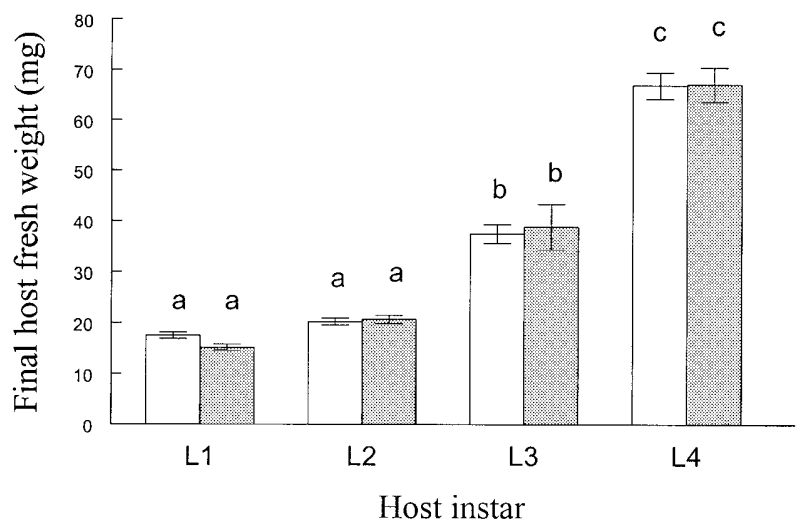

Fig. 4. The relationship between host instar at parasitism and terminal mass (after larval parasitoid egression) in $\mathrm{mg}$ in the interaction between Microplitis mediator and Pseudoplusia includens. Open bars = hosts producing male wasps, and shaded bars $=$ hosts producing female wasps. Line bars $=$ standard error of the mean. Bars with different letters are significantly different $(P<0.05$; Tukey tests). Sample sizes as in Fig. 2.

cantly with offspring $\operatorname{sex}\left(F_{1,221}=0.12, P=0.733\right)$. The amount of host tissues consumed by larvae of $M$. mediator was a dynamic function of host stage parasitized; wasps consumed a greater fraction of the mass of early host instars compared with later instars, which is characteristic species in the higher Microgastrinae (Harvey \& Strand, 2002). Typically, there was an exponential increase in the terminal size of the host as a function of instar at parasitism, with hosts parasitized as L4 some three to four times larger than hosts parasitized as L1 and L2. There was also a remarkable congruity in the final size of hosts that produced male and female offspring (Fig. 4).

\section{DISCUSSION}

The results of this investigation reveal that host quality, in terms of survival of $M$. mediator, is largely independent of host instar parasitized (with the exception of the final instar, which is entirely unsuitable). Offspring sex ratios were also uniform, with males accounting for approximately $60 \%$ of progeny that successfully emerged across different host instars. By contrast, $M$. mediator exhibits sexual dimorphisms in size and development time that are atypical of most parasitoids studied to date. Irrespective of host instar at parasitism, male wasps are consistently larger than female wasps (in terms of fresh weight) but complete their development significantly earlier. In contrast, male wasps for most other species studied to date develop faster than females (or there is no difference in this parameter) but are smaller at eclosion (Hurlbutt, 1987). Even amongst closely related braconid species in the higher Microgastrinae, the development pattern observed in M. mediator is exceptional (Table 1).

Further comparisons of weight and development time ratios between male and female wasps revealed that these relationships were isometric across different instars of $P$. includens. Independent of sex, however, parasitoid size increased with host size while development time was longer in small (L1) versus large (L4) hosts. Longer 
TABLE 1. Approximate fresh weight range of different instars of Pseudoplusia includens parasitized by Microplitis mediator. Each instar was parasitized on the first day post-moulting; the larval development of $P$. includens is photoperiodically gated and the duration of instars 1 to 4 was two days per instar.

\begin{tabular}{cc}
\hline Host instar & Weight range $(\mathrm{mg})$ \\
\hline L1 & $0.1-0.2$ \\
L2 & $0.4-0.8$ \\
L3 & $2.0-3.5$ \\
L4 & $12.0-20.0$ \\
\hline
\end{tabular}

development times in smaller hosts commonly occurs among koinobiont (but not idiobiont) parasitoids (Pettit \& Wietlisbach, 1993; Harvey et al., 1994, 2000; Croft \& Copland, 1995; Harvey \& Strand, 2002).

The "typical" development pattern in parasitoids is one where emerging female parasitoids are larger than male conspecifics but take longer to complete their development (Hurlbutt, 1987; Godfray, 1994; Mackauer, 1996). In koinobionts, this variation is frequently attributed to differing selection pressures operating on male and female size, with females benefiting more in terms of this parameter (Godfray, 1994). To achieve a larger size, though, female parasitoid larvae must extend their period of larval development in growing hosts, allowing them to accrue more resources than male offspring but at the cost of extending their development time (Model A, Fig. 5, from Mackauer et al., 1997). An interesting deviation from this hypothesis was proposed by Gunasena et al. (1989), who suggested that some koinobionts may differentially regulate host growth with offspring sex such that hosts containing female progeny grow larger (and thus provide more resources) than hosts containing male progeny. However, this does not appear to be the case for $M$. mediator, because there was not a significant difference in the terminal mass of hosts producing male and female progeny.

Two mechanisms could explain the apparent contradiction in sexual dimorphism between adult size and development time in $M$. mediator. In the first mechanism, the rate of resource acquisition during larval parasitoid development differs markedly between the two sexes, with males growing much more rapidly, pupating earlier, and completing development faster than female wasps (Model B, Fig. 5). In the second mechanism, the rate of resource acquisition by parasitoid larvae is moreor-less independent of offspring sex, but pupal duration is longer in female than in male wasps (Model C, Fig. 5 ). Because pupae do not feed or grow, they are constantly losing mass through the combined processes of respiration (metabolic activity) and desiccation, such that pupal weight declines linearly with age prior to eclosion (Sequeira \& Mackauer, 1992; Harvey et al., 1994). Female wasps presumably remain in the cocoons as pharate adults and continue to lose mass after male wasps have already eclosed.

Based on our results, the second pattern most closely approximates the development of $M$. mediator. In this species, the longer overall development time in female
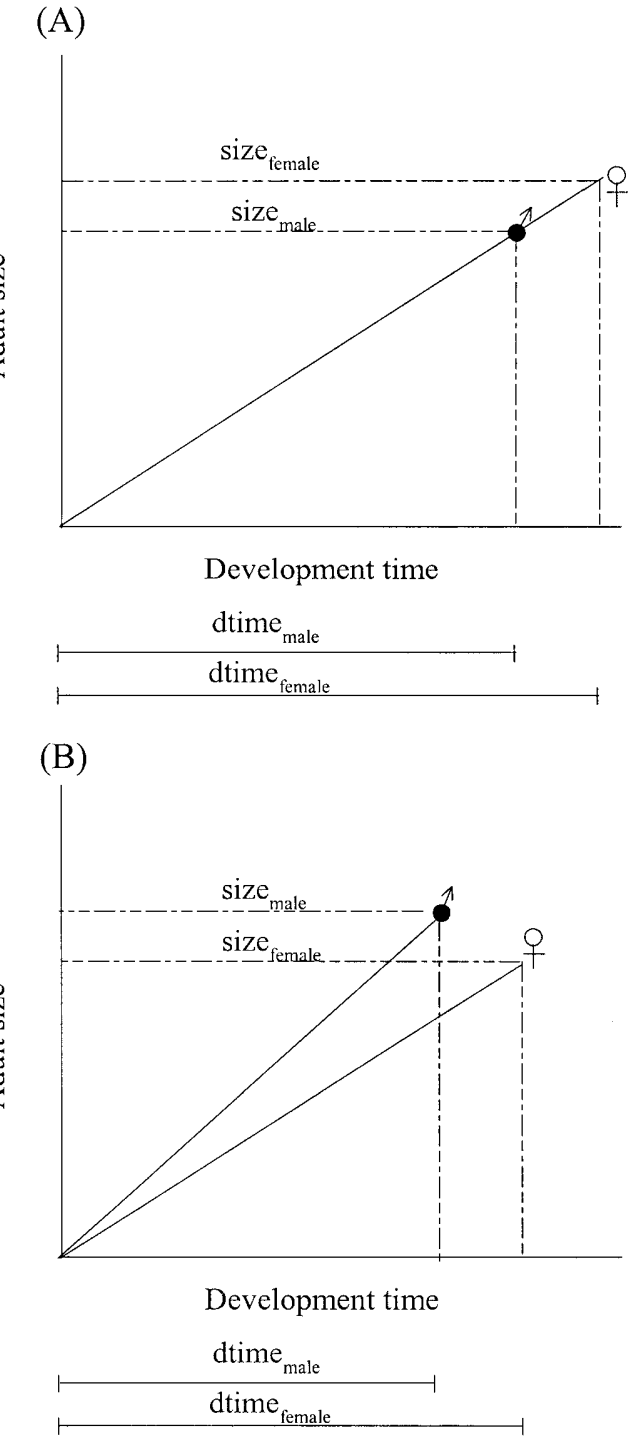

(C)

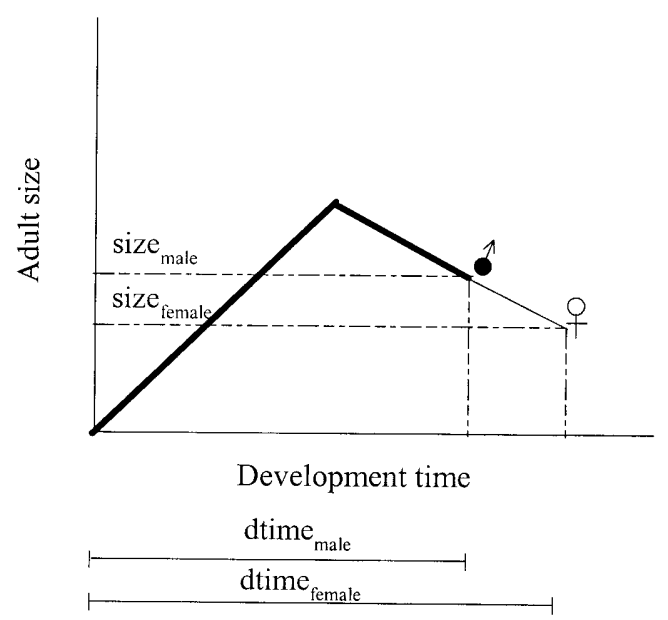

Fig. 5. Graphical models (a-c), illustrating possible alternative pathways explaining sexual dimorphisms in development time and size in koinobiont parasitoids. The models assume that each sex utilises a given amount of host resources differently, based on variation in the degree with which selection affects male and female parasitoid fitness. For a detailed description of each model, refer to results and discussion. 
TABLE 2. Comparison of sexual dimorphisms in development time and body size in a selected number of closely related parasitoid species in the higher Microgastrinae (= Braconidae). All parasitoids are solitary species unless otherwise indicated.

\begin{tabular}{|c|c|c|c|c|c|c|}
\hline Parasitoid species & Host species & Host instar & $\begin{array}{c}\text { Size } \\
\text { measure }\end{array}$ & $\begin{array}{l}\text { Size pattern } \\
\text { observed }\end{array}$ & $\begin{array}{c}\text { Development } \\
\text { time pattern } \\
\text { observed }\end{array}$ & Reference \\
\hline Microplitis mediator & Pseudoplusia includens & L1-L4 & FW & $\mathrm{M}>\mathrm{F}$ & $\mathrm{M}<\mathrm{F}$ & This study \\
\hline Microplitis croceipes & Heliothis virescens & $\mathrm{L} 2$ & FW & $\mathbf{M}=\mathbf{F}$ & $\mathrm{M}<\mathrm{F}$ & Harvey \& Strand (2002) \\
\hline Microplitis croceipes & Heliothis virescens & L1-L5 & $\mathrm{HCW}$ & $\mathrm{M} \geq \mathrm{F}$ & $\mathrm{M}<\mathrm{F}$ & Hopper (1986) \\
\hline Microplitis demolitor & Pseudoplusia includens & L1-L4 & $\mathrm{DM}$ & $\mathrm{M}=\mathrm{F}$ & $\mathrm{M}<\mathrm{F}$ & Harvey et al. (2000) \\
\hline Microplitis tristis* & Haden bicruris & L1-L5 & FW & $\mathrm{M}<\mathrm{F}$ & $\mathrm{M}<\mathrm{F}$ & J. Elzinga (unpublished) \\
\hline Cotesia marginiventris & Spodoptera exigua & $\mathrm{L} 2$ & FW & $\mathrm{M}<\mathrm{F}$ & $\mathrm{M}<\mathrm{F}$ & $\begin{array}{l}\text { Sznajder \& Harvey } \\
\quad \text { (unpublished) }\end{array}$ \\
\hline Cotesia glomerata* & $\begin{array}{l}\text { Pieris rapae } \\
\text { P. brassicae }\end{array}$ & L1-L3 & $\mathrm{DM}$ & $\mathrm{M}<\mathrm{F}$ & $\mathrm{M}<\mathrm{F}$ & Harvey (2000) \\
\hline Cotesia glomerata* & Pieris brassicae & $\mathrm{L} 1$ & $\mathrm{DM}$ & $\mathrm{M}<\mathrm{F}$ & $\mathrm{M}=\mathrm{F}$ & Brodeur et al. (1998) \\
\hline Cotesia rubecula & Pieris rapae & $\mathrm{L} 1$ & $\mathrm{DM}$ & $\mathrm{M}<\mathrm{F}$ & $\mathrm{M}<\mathrm{F}$ & Brodeur et al. (1998) \\
\hline Cotesia rubecula & Pieris brassicae & L1 & DM & $\mathrm{M}<\mathrm{F}$ & $\mathrm{M}=\mathrm{F}$ & Brodeur et al. (1998) \\
\hline Cotesia melanoscela & Lymantria dispar & L1 & $\mathrm{TL}$ & $\mathrm{M}<\mathrm{F}$ & $\mathrm{M}<\mathrm{F}$ & Kruse \& Raffa (1999) \\
\hline Cotesia congregata* & Manduca sexta & L1 & FW & $\mathrm{M}<\mathrm{F}$ & $?$ & Beckage \& Riddiford (1983) \\
\hline Cotesia plutellae & Plutella xylostella & L2-L4 & $?$ & $?$ & $\mathrm{M}<\mathrm{F}$ & Kawaguchi \& Tanaka (1999) \\
\hline Cotesia vestalis* & Melitea cinxia & L5 & FW & $\mathrm{M}<\mathrm{F}$ & $\mathrm{M}=\mathrm{F}$ & $\begin{array}{l}\text { Harvey \& van Nouhuys } \\
\quad \text { (unpublished) }\end{array}$ \\
\hline Cotesia urabae & Uraba lugens & L1-L3 & FW & $\mathrm{M}<\mathrm{F}$ & $\mathrm{M}<\mathrm{F}$ & Allen \& Keller (1991) \\
\hline
\end{tabular}

Legend: $\mathrm{DM}=$ dry mass, $\mathrm{FW}=$ fresh weight, $\mathrm{HCW}=$ head capsule width, $\mathrm{TL}=$ hind tibia length, $\mathrm{M}=$ male, $\mathrm{F}=$ female.

* = gregarious species

than in male wasps was attributable to an extended pupal period in females. However, it is unlikely that this mechanism fully explains the $10-15 \%$ difference in adult male and female body mass, although it may be a contributing factor. Given that the difference in development time between males and females amounted to about one-half day, and that the female wasps remain immobile in their cocoons during this time, the actual amount of fresh weight lost would likely be no more than about $5 \%$. Most importantly, each of the models needs further testing (and refining) before it is possible to fully understand the various mechanisms determining size and development time dimorphisms in $M$. mediator and other parasitoids.

For koinobiont parasitoids attacking small, nutritionally suboptimal hosts, it is often assumed that an increase in body size is consistent with extended development time (or compensatory increases in rates of larval growth) and vice versa, trade-offs that are clearly contradicted in $M$. mediator. The extended period of pupal development (at the expense of body size) in this species may be adaptive in two respects. First, many parasitoids are known to exhibit differing periods of pre-oviposition behavior, which are determined by physiological constraints on rates of egg-maturation and ovulation (Godfray, 1994). Synovigenic parasitoids may emerge with few or no available eggs to oviposit and are limited by the rate at which metabolic resources are allocated for egg production. Delaying emergence until sufficient eggs are available may substantially reduce the metabolic costs associated with activity while remaining in the cocoon may additionally decrease predation risk and other mortality-related factors.

Second, a number of parasitoids are known to exhibit "complementary sex determination" (CSD), whereby diploid male wasps may develop from fertilized eggs (Whiting, 1939). Sex determination in species exhibiting CSD is based on homozygosity at the sex locus (or loci), with individuals hemizygous (= haploid) or homozygous at the sex locus developing into males and heterozygous individuals developing into females. Since diploid males are almost always sterile or inviable, mating among individuals that share sex alleles will have a very negative effect on fitness, and will favor mating strategies that promote outcrossing and minimize mating among siblings. CSD is known to occur in several ichneumonoid parasitoids including the gregarious idiobiont, Habrobracon hebetor (Heimpel et al., 1999), and in the solitary koinobionts, Diadegma chrysostictos (Butcher et al., 2000) and Venturia canescens (Beukeboom, 2001). Female $H$. hebetor reportedly remain in cocoons as fully developed adults in a semi-active state for at least $24 \mathrm{~h}$ after male siblings have emerged and dispersed (Ode et al., 1995). By analogy, delayed emergence of $M$. mediator females could be favored for similar reasons.

The majority of published studies report that male wasps are smaller than female conspecifics (or else there is no difference in this parameter) and complete their development more rapidly, based on the traditional assumption that large females benefit more in terms of fitness than large males (Charnov, 1982; Hurlbutt, 1987; Mackauer, 1996). However, this study indicates that 
selection for traits affecting fitness, such as increased offspring size and reduced development time, may be more important in male than in female wasps, leading to dimorphisms in these traits that contrast with model predictions (e.g. Charnov, 1982). In view of the dearth of comprehensive data available, future studies examining size-fitness relationships in parasitoids need to clarify the relative costs and benefits of variation in multiple traits influencing fitness rather than a single one. Size has often been regarded as the sole, or at least most important, fitness currency in parasitoids without considering developmental constraints which increase the cost of body size at the expense of survival in the field (Harvey \& Strand, 2002). Furthermore, investigating factors affecting male as well as female fitness will undoubtedly enhance our understanding of complex life-history patterns in this fascinating group of insects.

ACKNOWLEDGEMENTS. We wish to thank Kristy Kadash for her help with insect rearing and experiments. Mark Jervis, Wim van der Putten, Jacintha Ellers and Manfred Mackauer are also gratefully acknowledged for their critical review of earlier versions of the manuscript. The work was funded by Hatch project 3929, NIH grant R01A132617, and NSF grant IBN9514231 grant to MRS.

\section{REFERENCES}

Allen G.R. \& Keller M.A. 1991: Uraba lugens (Lepidoptera, Noctuidae) and its parasitoids (Hymenoptera: Braconidae) temperature, host size, and development. Environ. Entomol. 20: 458-469.

ArThur A.P. \& MAson P.G. 1986: Life history and immature stages of the parasitoid Microplitis mediator (Hymenoptera: Braconidae), reared on the Bertha armyworm Mamestra configurata (Lepidoptera: Noctuidae). Can. Entomol. 118: 487-491.

BeCKage N.E. \& RiddFord L.M. 1983: Growth and development of the endoparasitic wasp Apanteles congregatus: dependence on host nutritional status and parasite load. Physiol. Entomol. 8: 231-241.

Beukeвoom L.W. 2001: Single-locus complementary sex determination in the ichneumonid Venturia canescens (Gravenhorst) (Hymenoptera). Neth. J. Zool. 51: 1-15.

Bernal J.S., Gillogly P.O. \& Griset J. 2001: Family planning in a stemborer parasitoid: sex ratio, brood size and size-fitness relationships in Parallorhogas pyralophagus (Hymenoptera: Braconidae), and implications for biological control. Bull. Entomol. Res. 91: 255-264.

BRODEUR J. \& VET L.E.M. 1994: Usurption of host behaviour by a parasitic wasp. Anim. Behav. 48: 187-192.

Brodeur J., Geervliet J.B.F. \& Vet L.E.M. 1998: Effects of Pieris host species on life history parameters in a solitary specialist and gregarious generalist parasitoid (Cotesia species). Entomol. Exp. Appl. 86: 145-152.

Butcher R.D.J., WhitField W.G.F. \& Hubbard S.F. 2000: Complementary sex determination in the genus Diadegma (Hymenoptera: Ichneumonidae). J. Evol. Biol. 13: 593-606.

CAlDER W.A. 1984: Size, Function, and Life History. Harvard University Press, Cambridge, Mass, $448 \mathrm{pp}$.

Charnov E.L. 1982: The Theory of Sex Allocation. Princeton University Press, Princeton, New Jersey, $355 \mathrm{pp}$.

Corrigan J.E. \& Lashomb J.H. 1990: Host influences on the bionomics of Edovum puttleri (Hymenoptera: Eulophidae): effects on size and reproduction. Environ. Entomol. 19: $1496-1502$.

Croft P. \& Copland M.J.W. 1995: The effect of host instar on the size and sex ratio of the endoparasitoid Dacnusa sibirica. Entomol. Exp. Appl. 74: 121-124.

Ellers J., Bax M. \& van Alphen J.J.M. 2001: Seasonal changes in female size and its relation to reproduction in the parasitoid Asobara tabida. Oikos 92: 309-314.

Fagerstrom T. \& WikLund C. 1982: Why do males emerge before females? Protandry as a mating strategy in male and female butterflies. Oecologia 52: 164-166.

Fairbairn D.J. \& Preziosi R.F. 1994: Sexual selection and the evolution of allometry for sexual size dimorphism in the water strider, Aquarius remigis. Am. Nat. 144: 101-118.

Gerling D., Orion T. \& Delarea Y. 1990: Eretmoceros penetration and immature development: a novel approach to overcome host immunity. Arch. Insect Biochem. Physiol. 13: 247-253

Griselin M.T. 1974: The Economy of Nature and the Evolution of Sex. University of California Press, Berkeley, $346 \mathrm{pp}$.

Godfray H.C.J. 1994: Parasitoids: Behavioral and Evolutionary Ecology. Princeton University Press, Princeton, New Jersey, $488 \mathrm{pp}$.

Greenwoon P.J. \& Wheeler P. 1985: The evolution of sexual size dimorphism in birds and mammals: a "hot blooded" hypothesis. In: Greenwood P.G., Harvey P.H. \& Slatkin M. (eds): Evolution: Essays in Honour of John Maynard Smith. Cambridge University Press, Cambridge, pp. 287-299.

Gunasena G.H., Vinson S.B. \& Williams H.J. 1989: Interrelationships between growth of Heliothis virescens (Lepidoptera: Noctuidae) and that of its parasitoid, Campoletis sonorensis (Hymenoptera: Ichneumonidae). Ann. Entomol. Soc. Am. 82: 187-191.

Hardy I.C.W., Griffiths N.T. \& Godfray H.C.J. 1992: Clutch size in a parasitoid wasp: a manipulation experiment. J. Anim. Ecol. 61: 121-129.

HARVEY J.A. 2000: Dynamic effects of parasitism by an endoparasitoid wasp on the development of two host species: implications for host quality and parasitoid fitness. Ecol. Entomol. 25: 267-278.

HARVEY J.A. \& Gols G.J.Z. 1998: The influence of host quality on progeny and sex allocation in the pupal ectoparasitoid, Muscidifurax raptorellus (Hymenoptera: Pteromalidae). Bull. Entomol. Res. 88: 299-304.

HarVey J.A. \& Strand M.R. 2002: The developmental strategies of endoparasitoid wasps vary with host feeding ecology. Ecology 83: 2349-2451.

Harvey J.A., Harvey I.F. \& Thompson D.J. 1994: Flexible larval growth allows use of a range of host sizes by a parasitoid wasp. Ecology 75: 1420-1428.

HaRVEY J.A., KadAsh K. \& STRAND M.R. 2000: Differences in larval feeding behavior correlate with altered developmental strategies in two parasitic wasps: implications for the sizefitness hypothesis. Oikos 88: 621-629.

Heimpel G.E., Antolin M.F. \& StRand M.R. 1999: Diversity of sex-determining alleles Bracon hebetor. Heredity $\mathbf{8 2}$ : 282-291.

Hernz K.M. 1996: Host size selection and sex allocation behaviour among parasitoid trophic levels. Ecol. Entomol. 21: 218-226.

Hopper K.R. 1986: Preference, acceptance, and fitness components of Microplitis croceipes attacking various instars of Heliothis virescens. Environ. Entomol. 15: 274-280.

Hurlbutt B.L. 1987: Sexual size dimorphism in parasitoid wasps. Biol. J. Linn. Soc. 30: 63-89. 
Kadash K., Harvey J.A. \& Strand M.R. 2003: Cross-protection experiments with parasitoids in the genus Microplitis (Hymenoptera: Braconidae) suggest a high level of specificity in their associated bracoviruses. J. Insect Physiol. 49: $473-482$.

Karubian J. \& Swaddle J.P. 2001: Selection on females can create "larger males". Proc. Roy. Soc. Lond. B. 268: 725-728.

KaWAGUCHI M. \& TANAKA T. 1999: Biological characteristics of a larval endoparasitoid, Cotesia plutellae (Hymenoptera: Braconidae): Host stage preference, subsequent sex ratio of progeny and mate location of males. Appl. Entomol. Zool. 34: $213-221$

Kruse J.J. \& RafFA K.F. 1999: Effect of food plant switching by a herbivore and its parasitoid: Cotesia melanoscela development in Lymantria dispar exposed to reciprocal dietary crosses. Ecol. Entomol. 24: 37-45.

MACKAUER M. 1996: Sexual size dimorphism in solitary parasitoid wasps: influence of host quality. Oikos 76: 265-272.

Mackauder M. \& SequeIra R. 1993: Patterns of development in insect parasites. In: Beckage N.E., Thompson S.N. \& Federici B.A. (eds): Parasites and Pathogens of Insects, Vol. 1. Academic Press, New York, pp. 1-23.

Mackauer M., Sequetra R. \& Otto M. 1997: Growth and development in parasitoid wasps: adaptation to variable host resources. In: Detner K., Bauer G. \& Volkl W. (eds): Vertical Food Web Interactions. Evolutionary Patterns and Driving Forces. (Ecological Studies 130). Springer, Berlin, Heidelberg, New York, pp. 191-203.

Mayhew P.J. 1998: The evolution of gregariousness in parasitoid wasps. Proc. Roy. Soc. Lond. B. 265 : 1-7.

Ode P.J, Antolin M.F. \& StRAND M.R. 1995: Brood-mate avoidance in the parasitic wasp Bracon hebetor. Anim. Behav. 49: $1239-1248$.

Parker G.A. \& Courtney S.P. 1984: Models of clutch size in insect oviposition. Theor. Pop. Biol. 26: 27-48.

Pettit F.L. \& Wietlisbach D.O. 1993: Effects of host instar and size on parasitization efficiency and life history parameters of Opius dissitus. Entomol. Exp. Appl. 66: 227-236.

Rensch B. 1959: Evolution Above the Species Level. Columbia University Press, New York, 419 pp.

SCHMidT J.M., \& SMITH J.J.B. 1985: Host volume measurement by the parasitoid wasp Trichogramma minutum: the roles of curvature and surface area. Entomol. Exp. Appl. 39: 213-221.
Schulter-Hostedde A.I., Millar J.S. \& Hickling G.J. 2001: Sexual dimorphism in body composition of small mammals. Can. J. Zool. 79: 1016-1020.

SequeIRA R. \& Mackauer M. 1992: Nutritional ecology of an insect host-parasitoid association: the pea aphid-Aphidius ervi system. Ecology 73: 183-189.

SHINE R. \& CREWS D. 1988: Why male garter snakes have small heads - the evolution and endocrine control of sexual dimorphism. Evolution 10: 1105-1110.

STRAND M.R. 1988: Variable sex ratio strategy of Telenomus heliothidis (Hymenoptera: Scelionidae): the influence of host and conspecific density. Oecologia 77: 219-224.

StRAND M.R. 1990: Characterization of larval development in Pseudoplusia includens (Lepidoptera: Noctuidae). Ann. Entomol. Soc. Am. 83: 538-544.

Strand M.R. 2000: Developmental traits and life-history evolution in parasitoids. In: Hochberg M.E. \& Ives A.R. (eds): Parasitoid Population Biology. Princeton University Press, Princeton, New Jersey, pp. 139-162.

STRAND M.R. 2002: The interactions between larval stage parasitoids and their hosts. In: Sukdeo M., Campbell J. \& Lewis E. (eds): Behavioral Ecology of Parasites. CABI Press, London, pp. 129-152.

TAKAGI M. 1986: The reproductive strategy of the gregarious parasitoid, Pteromalus puparum (Hymenoptera: Pteromalidae). Host size discrimination and regulation of the number and sex ratio of progeny in a single host. Oecologia 70: 321-325.

VISSER M.E. 1994: The importance of being large: the relationship between size and fitness in females of the parasitoid Aphaereta minuta (Hymenoptera: Braconidae). J. Anim. Ecol. 63: 963-978.

Vollrath F. \& Parker G.A. 1992: Sexual dimorphism and distorted sex-ratios in spiders. Nature 360: 156-159.

WAAGE J.K. \& GODFRAY H.C.J. 1985: Reproductive strategies and population ecology of insect parasitoids. In: Sibly R.M. \& Smith R.H. (eds): Behavioural Ecology (British Ecological Society Symposium 25). Blackwell Scientific Publications, Oxford, pp. 449-470.

WERREN J.H. 1984: A model for sex ratio selection in parasitic wasps: Local mate competition and host quality effects. Neth. J. Zool. 34: 81-96.

Whitrng P.W. 1939: Sex determination and reproductive economy in Habrobracon. Genetics 24: 110-111.

Received February 12, 2003; revised July 16, 2003; accepted September 14, 2003 